\title{
Experimental and Analytical Study on Torsional Behaviour Of RC Flanged Beams Strengthened With Glass FRP \\ K. Gowthami ${ }^{1}$, D. Mohammed Rafi' ${ }^{2}$, K. Mohammed Rasheed ${ }^{3}$
}

${ }^{* 1}$ M.Tech Student, Chiranjeevi Reddy Institute of Engineering \& Technology, Anantapur, Andhra Pradesh, India

²,3 Assistant Professor, Civil Engineering Department, Chiranjeevi Reddy Institute of Engineering \& Technology, Anantapur, Andhra Pradesh, India

\begin{abstract}
Environmental degradation, increased service loads, reduced capacity due to aging, degradation owing to poor construction materials and workmanships and conditional need for seismic retrofitting have demanded the necessity for repair and rehabilitation of existing structures. Fibre reinforced polymers has been used successfully in many such applications for reasons like low weight, high strength and durability. Many previous research works on torsional strengthening were focused on solid rectangular RC beams with different strip layouts and different types of fibres. Various analytical models were developed to predict torsional behavior of strengthened rectangular beams and successfully used for validation of the experimental works. But literature on torsional strengthening of RC T- beam is limited. In the present work experimental study was conducted in order to have a better understanding the behavior of torsional strengthening of solid RC flanged T-beams. An RC T-beam is analyzed and designed for torsion like an RC rectangular beam; the effect of concrete on flange is neglected by codes. In the present study effect of flange part in resisting torsion is studied by changing flange width of controlled beams_ The other parameters studied are strengthening configurations and fiber orientations. The objective of present study is to evaluate the effectiveness of the use of epoxy-bonded GFRP fabrics as external transverse reinforced to reinforced concrete beams with flanged cross sections (T-beam) subjected to torsion. Torsional results from strengthened beams are compared with the experimental result of the control beams without FRP application. The study shows remarkable improvement in torsional behavior of all the GFRP strengthen beams. The experimentally obtained results are validated with analytical model presented by A.Deifalla and A. Ghobarah and found in good agreement.
\end{abstract}

Keywords : Durability, FRP, Flanged beam, GFRP, Rehabilitation, Torsion

\section{INTRODUCTION}

Modern civilization relies upon the continuing performance of its civil engineering infrastructure ranging from industrial buildings to power stations and bridges. For the satisfactory performance of the existing structural system, the need for maintenance and strengthening is inevitable. During its whole life span, nearly all engineering structures ranging from residential buildings, an industrial building to power stations and bridges faces degradation or deteriorations. The main causes for those deteriorations are environmental effects including corrosion of steel, gradual loss of strength with ageing, variation in temperature, freeze-thaw cycles, repeated high intensity loading, contact with 
chemicals and saline water and exposure to ultraviolet radiations. Addition to these environmental effects earthquakes is also a major cause of deterioration of any structure. This problem needs development of successful structural retrofit technologies. So it is very important to have a check upon the continuing performance of the civil engineering infrastructures.

The structural retrofit problem has two options, repair/retrofit or demolition/reconstruction. Demolition or reconstruction means complete replacement of an existing structure may not be a cost-effective solution and it is likely to become an increasing financial burden if upgrading is a viable alternative. Therefore, repair and rehabilitation of bridges, buildings, and other civil engineering structures is very often chosen over reconstruction for the damage caused due to degradation, aging, lack of maintenance, and severe earthquakes and changes in the current design requirements. Previously, the retrofitting of reinforced concrete structures, such as columns, beams another structural elements, was done by removing and replacing the low quality or damaged concrete or/and steel reinforcements with new and stronger material.

In addition, FRP manufacturing offers a unique opportunity for the development of shapes and forms that would be difficult or impossible with the conventional steel materials. Although the fibers and resins used in FRP systems are relatively expensive compared with traditional strengthening materials, labour and equipment costs to install FRP systems are often lower. FRP systems can also be used in areas with limited access where traditional techniques would be impractical. Several investigators took up concrete beams and columns retrofitted with carbon fiber reinforced polymer (CFRP) glass fiber reinforced polymer (GFRP) composites in order to study the enhancement of strength and ductility, durability, effect of confinement, preparation of design guidelines and experimental investigations of these members.

\section{TORSIONAL STRENGHTENING OF BEAMS}

Early efforts for understanding the response of plain concrete subjected to pure torsion revealed that the material fails in tension rather than shear. Structural members curved in plan, members of a space frame, eccentrically loaded beams, curved box girders in bridges, spandrel beams in buildings, and spiral staircases are typical examples of the structural elements subjected to torsional moments and torsion cannot be neglected while designing such members. Structural members subjected to torsion are of different shapes such as $\mathrm{T}$-shape, inverted L-shape, double T-shapes and box sections. These different configurations make the understanding of torsion in RC members of complex task. In addition, torsion is usually associated with bending moments and shearing forces, and the interaction among these forces is important.

Spandrel beams, located at the perimeter of buildings, carry loads from slabs, joists, and beams from one side of the member only. This loading mechanism generates torsional forces that are transferred from the spandrel beams to the columns. Reinforced concrete (RC) beams have been found to be deficient in torsional capacity and in need of strengthening. These deficiencies occur for several reasons, such as insufficient stirrups resulting from construction errors or inadequate design, reduction in the effective steel area due to corrosion, or increased demand due to a change in occupancy. Similar to the flexure and shear strengthening, the FRP fabric is bonded to the tension surface of the $\mathrm{RC}$ members for torsion strengthening. In the case of torsion, all sides of the member are subjected to diagonal tension and 
therefore the FRP sheets should be applied to all the faces of the member cross section. However, it is not always possible to provide external reinforcement for all the surfaces of the member cross section.

\section{ADVANTAGES AND DISADVANTAGES OF FRP}

\subsection{Advantages}

There have been several important advances in materials and techniques for structural rehabilitation, including a new class of structural materials such as fiber-reinforced polymers (FRP). One such technique for strengthening involves adding external reinforcement in the form of sheets made of FRP. Advanced materials offer the designer a new combination of properties not available from other materials and effective rehabilitation systems. Strengthening structural elements using FRP enables the designer to selectively increase their ductility, flexure, and shear capacity in response to the increasing seismic and service load demands. For columns, wrapping with FRP can significantly improve the strength and ductility.

A potent advantage of using FRP as an alternate external confinement to steel is the high strength to weight ratio comparisons. In order to achieve an equivalent confinement, FRP plates are up to $20 \%$ less dense than steel plates and are at least twice as strong, if not more. Manufacture of modern composites is, then, possible in reduced sections and allows composite plates to be shaped on-site. The lower density allows easier placement of confinement in application. Design of external confinement to a structure should be made with conservative adjustments to the primary structures dead weight load. Changes of the stiffness of members should be considered when redesigning the structure. The improved behaviour of FRP wrapped members reduces the strains of internal steel reinforcement thereby delaying attainment of yielding. Much like internal steel confinement in longitudinal and lateral axes, external confinement exerts a similar pressure on the concrete as well as to the internal steel. Furthermore, FRP have high corrosive resistance equating to material longevity whilst within aggressive environments. Such durability makes for potential savings in long-term maintenance costs.

\subsection{Disadvantages}

With the above advantages FRP does also have some disadvantages as follows: The main disadvantage of externally strengthening structures with fiber composite materials is the risk of fire, vandalism or accidental damage, unless the strengthening is protected. As FRP materials are lightweight they tend to poses aerodynamic instability. Retrofitting using fiber composites are more costly than traditional techniques. Experience of the long-term durability of fiber composites is not yet available. This may be a disadvantage for structures for which a very long design life is required but can be overcome by appropriate monitoring. This technique need highly trained specialists. More over there is lack of standards and design guides.

\subsection{LITERATURE REVIEW ON TORSIONAL STRENGTHENING OF RC BEAM}

Most of the research projects investigating the use of FRP focused on enhancing the flexural and shear behaviour, ductility, and confinement of concrete structural members. A limited number of mostly experimental studies were conducted to investigate torsion strengthening of RC members.

Ghobarah et al. (2002) conducted an experimental investigation on the improvement of the torsional 
resistance of reinforced concrete beams using fiberreinforced polymer (FRP) fabric. A total of 11 beams were tested. Three beams were designated as control specimens and eight beams were strengthened by FRP wrapping of different configuration and then tested. Both glass and carbon fibers were used in the torsional resistance upgrade. Different wrapping designs were evaluated. The reinforced concrete beams were subjected to pure torsional moments. The load, twist angle of the beam, and strains were recorded. Improving the torsional resistance of reinforced concrete beams using FRP was demonstrated to be viable. The effectiveness of various wrapping configurations indicated that the fully wrapped beams performed better than using strips. The $45^{\circ}$ orientation of the fibers ensures that the material is efficiently utilized.

Panchacharam and Belarbi (2002) experimentally found out that externally bonded GFRP sheets can significantly increase both the cracking and the ultimate torsional capacity. The behaviour and performance of reinforced concrete member strengthened with externally bonded Glass FRP (GFRP) sheets subjected to pure torsion was presented. The variables considered in the experimental study include the fiber orientation, the number of beam faces strengthened (three or four), the effect of number of FRP plies used, and the influence of anchors in U-wrapped test beams. Experimental results reveal that externally bonded GFRP sheets can significantly increase both the cracking and the ultimate torsional capacity. Predicted strengths of the test beams using the proposed theoretical models were found to be in good agreement with the experimental results.

Salom et al. (2004) conducted both experimental and analytical programs focused on the torsional strengthening of reinforced concrete spandrel beams using composite laminates. The variables considered in this study included fiber orientation, composite laminate, and effects of a laminate anchoring system. Current torsional strengthening and repair methods are time and resource intensive, and quite often very intrusive. The proposed method however, uses composite laminates to increase the torsional capacity of concrete beams.

\section{EXPERIMENTAL STUDY}

To study the most influential strengthening variables on torsional behavior a total of eleven medium scale reinforced concrete beams of $1900 \mathrm{~mm}$ long were constructed for this work. T-shaped beams, which are sorted in three groups (T2, T3 and T4) and were tested under combined bending torsion. Three numbers of beams are without torsional reinforcement were the control specimens and eight specimens were strengthened using epoxy-bonded glass FRP fabrics as external transverse reinforcemeat.

The cross-section of specimens was One beam were flanged beams with $\mathrm{T}$-shaped with dimensions $\mathrm{b}_{\mathrm{w}} / \mathrm{D} / \mathrm{bf} / \mathrm{df}=150 / 270 / 250 / 80 \mathrm{~mm}$ (beams of series $\mathrm{T} 2$ ). In the series- $\mathrm{B}$ five beam specimens were flanged beams, and the dimensions are bw/D/bf/df=150/270/350/80 (beams of series T3). And also another five beam specimens were $\mathrm{T}$ shaped cross-section and dimensions bw/D/bf/df=150/270/350/80 (beams of series T4). The cross-section of all beams has shown in fig 3.1

Each group comprises one control specimen without transverse reinforcement. Specimens T2C were the control specimen of group-A, it had only longitudinal reinforcement; four deformed bars of diameter $20 \mathrm{~mm}^{\wedge}$, and $10 \mathrm{~mm}^{\wedge}$, at the corners of the 
cross-section, and control specimen of T3C,and T4C of series six longitudinal deformed bars of diameter $20 \mathrm{~mm}^{\wedge}, 10 \mathrm{~mm}^{\wedge}$, and $8 \mathrm{~mm}^{\wedge}$, transverse bars of $8 \mathrm{~mm}^{\wedge}$ two legged stirrups. The other eight specimens of the experimental program included the same longitudinal reinforcement as the control specimens of their group and transverse reinforcement (steel stirrups).

Test beams were identified based on the following naming system. The first character in the name $R$ (Rectangular), $\mathrm{T}$ (T-section) is used to identify the cross/section of beam. Second character is the dimensions of the beam. The third two characters are used to specify the strengthening in web or flange or both (U or UA). Fourth character in the name (90, 45 ) is used to specify the fiber orientation with respect to the longitudinal axis of the beam.

\subsection{CASTING OF SPECIMENS.}

For conducting experiment, eleven reinforced concrete beam specimen of size as Shown in the fig (Length of main beam $(\mathrm{L})=1900 \mathrm{~mm}$, Breadth of main beam $\left(b_{\mathrm{w}}\right)=150 \mathrm{~mm}$, Depth of main beam $(\mathrm{D})=$ $270 \mathrm{~mm}$, Length of cantilever parts $=400 \mathrm{~mm}$, Width of cantilever part $=200 \mathrm{~mm}$, Depth of cantilever part $=$ $270 \mathrm{~mm}$, Distance of cantilever part from end of the beam $=350 \mathrm{~mm}$ ) and all having the same reinforcement detailing are cast. The mix proportion is 0.5 : $1: 1.67: 3.3$ for water, cement, fine aggregate and course aggregate is taken. The mixing is done by using concrete mixture. The beams were cured for 28 days. For each beam three cubes, two cylinders and two prisms were casted to determine the compressive strength of concrete for 28 days.

\subsection{Cement}

Cement is a material, generally in powered form, which can be made into a paste usually by the addition of water and, when molded or poured, will set into a solid mass. Numerous organic compounds used for an adhering, or fastening materials, are called cements, but these are classified as adhesives, and the term cement alone means a construction material. The most widely used of the construction cements is Portland cement. It is bluish-gray powered obtained by finely grinding the clinker made by strongly heating an intimate mixture of calcareous and argillaceous minerals. Portland Slag Cement (PSC) Konark Brand was used for this investigation. It is having a specific gravity of 2.96 .

\subsection{Fine Aggregate}

Fine aggregate is an accumulation of grains of mineral matter derived from disintegration of rocks. It is distinguished from gravel only by the size of the grains or particles, but is distinct from clays which contain organic material. Sand is used for making mortar and concrete and for polishing and sandblasting. Sands containing a little clay are used for making molds in foundries. Clear sands are employed for filtering water. Here, the fine aggregate/sand is passing through $4.75 \mathrm{~mm}$ sieve and having a specific gravity of 2.64 . The grading zone of fine aggregate is zone III as per Indian Standard specifications IS: 383-1970.

\subsection{Coarse Aggregate}

Coarse aggregates are the crushed stone is used for making concrete. The commercial stone is quarried, crushed, and graded. Much of the crushed stone used is granite, limestone, and trap rock. The coarse aggregates of two grades are used one retained on 10 $\mathrm{mm}$ size sieve and another grade contained aggregates retained on $20 \mathrm{~mm}$ size sieve. The maximum size of coarse aggregate was $20 \mathrm{~mm}$ and is having specific gravity of 2.88 grading confirming to IS: 383-1970.

\subsection{Water}


Water fit for drinking is generally considered good for making the concrete. Water should be free from acids, alkalis, oils, vegetables or other organic impurities. Soft water produces weaker concrete. Water has two functions in a concrete mix. Firstly, it reacts chemically with the cement to form a cement paste in which the inert aggregates are held in suspension until the cement paste has hardened. Secondly, it serves as a vehicle or lubricant in the mixture of fine aggregates and cement. Ordinary clean portable tap water is used for concrete mixing in all the mix.

\subsection{Reinforcing Steel}

High-Yield Strength Deformed (HYSD) bars confirming to IS $1786: 1985$. The longitudinal steel reinforcing bars were deformed, high-yield strength, with $209 \mathrm{~mm} 109 \mathrm{~mm}$ and $8 \mathrm{~mm}^{\wedge}$ diameter. The stirrups were made from deformed steel bars with 8 mm 9 diameter.

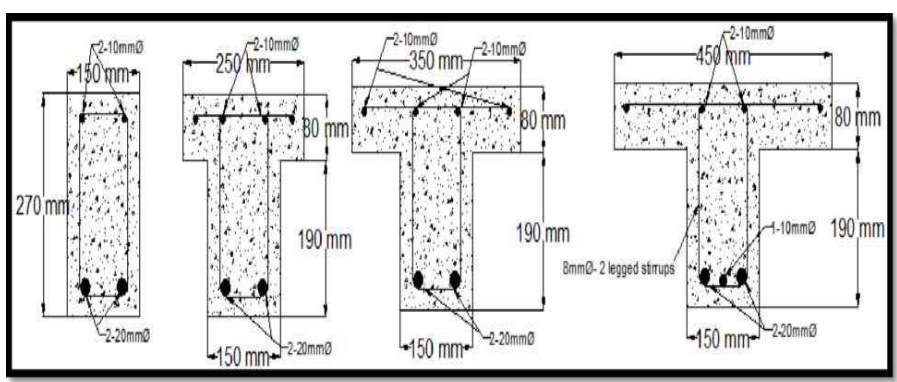

Figure 1 : Detailing of Reinforcement

\subsection{Mixing of Concrete}

Mixing of concrete is done thoroughly with the help of machine mixer so that a uniform quality of concrete was obtained.

\subsection{Compaction}

Compaction is done with the help of needle vibrator in all the specimens. And care is taken to avoid displacement of the reinforcement cage inside the form work. Then the surface of the concrete is levelled and smoothened by metal trowel and wooden float

\subsection{Curing Of Concrete}

Curing is done to prevent the loss of water which is essential for the process of hydration and hence for hardening. It also prevents the exposure of concrete to a hot atmosphere and to drying winds which may lead to quick drying out of moisture in the concrete and there by subject it to contraction stresses at a stage when the concrete would not be strong enough to resists them. Here curing is to be done by spraying water on the jute bags spread over the surface for a period of 7 days.

\subsection{Fiber Reinforced Polymer (FRP)}

Continuous fiber reinforced materials with polymeric matrix (FRP) can be considered as composite, heterogeneous, and anisotropic materials with a prevalent linear elastic behaviour up to failure. Normally, Glass and Carbon fibers are used as reinforcing material for FRP. Epoxy is used as the binding material between fiber layers. For this study, GFRP sheet was used during the tests i.e., a bidirectional FRP with the fiber oriented in both longitudinal and transverse directions, due to the flexible nature and ease of handling and application, the FRP sheets are used for torsional strengthening. Throughout this study, E-glass was used manufactured by Owens Corning.

\section{TEST RESULTS AND DISCUSSIONS}

\subsection{Experimental Results}

This chapter includes experimental results of all beams with different types of configurations and orientation of GFRP. Their behavior throughout the test is described using recorded data on torsional behavior and the ultimate load carrying capacity. The crack patterns and the mode of failure of each 
beam are also described in this chapter. All the beams are tested till complete failure. Beams T2C, T3C and T4C are the control beams. It is observed that the control beam had less load carrying capacity and high deflection values compared to that of the FRP strengthened beams. Group A beam T2C has $250 \mathrm{~mm}$ wide flange beam is considered as control beam. In group-Band group- $\mathrm{C}$, all beams are strengthened with $100 \mathrm{~mm}$ wide, four layered strips of GFRP fabrics with an clear spacing of $75 \mathrm{~mm}$. The different patterns of wrapping adopted are 90 degree fully wrapped, $45^{\circ}$ fully wrapped, U-wrapped, Uwrap with flange anchored with bolt.

\subsection{Failure Modes}

Different failure modes have been observed in the experiments. These include torsional shear failure due to GFRP rupture and debonding. Rupture of the FRP strips is assumed to occur if the strain in the FRP reaches its design rupture strain before the concrete reaches its maximum usable strain. GFRP debonding can occur if the force in the FRP cannot be sustained by the substrate. Load was applied on the two moment arm of the beams which is $0.375 \mathrm{~m}$ away from the main beam. At each increment of the load, deflections at $\mathrm{L} / 3, \mathrm{~L} / 2$ and $2 \mathrm{~L} / 3$ were observed and noted down with the help of six nos. of dial gauges. At each section two dial gauges were fixed to measure the displacement caused by twisting moment. The relative displacements divided by distance between dial gauges gives angle of twist. Section at $\mathrm{L} / 3$ was taken as sec- 1 , section at middle of beam as taken as sec- 2 , and section at $2 \mathrm{~L} / 3$ was taken as section 3.The loading arrangement was same for all the beams.
The experimental program of this study consists of eleven numbers of reinforced concrete $\mathrm{T}$ - beams with different flange widths tested under torsion. The main objective of this study is to investigate the effectiveness of the use of epoxy-bonded FRP fabrics as external transverse reinforcement. Based on presented experimental measurements and analytical predictions, the following conclusions were reached

$\checkmark$ Experimental results shows that the effect of flange width on torsional capacity of GFRP strengthened RC T-beams are significant.

$\checkmark$ Torsional strength increases with increase in flange area irrespective of beam strengthening with GFRP following different configurations schemes.

$\checkmark$ With $250 \mathrm{~mm}$ wide flange width increase in strength was $13 \%$, with $350 \mathrm{~mm}$ wide flange was $29 \%$ and for $450 \mathrm{~mm}$ wide flange was found to be $69 \%$. This is due to increase in area enclosed inside the critical shear path.

$\checkmark$ The cracking and ultimate torque of all strengthen beams were greater than those of the control beams.

$\checkmark$ The cracking and ultimate torque of all strengthen beams were greater than those of the control beams.

$\checkmark$ The increase in magnitude depends on the FRP strengthening configurations.

$\checkmark$ The maximum increase in torque was obtained for $90^{\circ}$ fully wrapped configurations. Increase of $133.33 \%$ to $116.67 \%$ in first cracking and $155.55 \%$ to $107.23 \%$ in ultimate torsion were recorded for series B beams and series $C$ beams respectively. 
[1]. CHAMPION, J. M. and JOST, P., 'Selfcompacting concrete: Expanding the possibility of Concrete Design and Placement', Concrete International, Vol.22, No.4, pp. 159-178, June 1998.

[2]. HEINE, HANS J. "Saving Dollars Through Sand Reclamation - Part 1," Foundry Management and Technology. 111:5 (May, 1983), pp.22-25

[3]. SUBRAMNIAN. S., CHATTOPADHYAY. D, "Experiments for mix - proportioning of self compacting concrete", The Indian Concrete Journal, Jan 2002.

[4]. K. SuvarnaLatha et al (2012), "Estimation of GGBS and HVFA Strength Efficiencies in Concrete with Age"International Journal of Engineering and Advanced Technology (IJEAT) ISSN: 2249 - 8958,Volume-2,

[5]. A.H.L.Swaroop et al (2013), "Durability Studies on Concrete with Fly Ash \&Ggbs" International Journal of Engineering Research and Applications (IJERA)ISSN: 2248-9622 Vol. 3, Issue 4, pp.285-28

[6]. BapugoudaPatil et al (2015), “Durability Studies on Sustainable Geopolymer Concrete" International Research Journal of Engineering and Technology (IRJET) e-ISSN: 2395-0056 Volume: 02 Issue: 04
K. Gowthami, D. Mohammed Rafi, K. Mohammed Rasheed, "Experimental and Analytical Study on Torsional Behaviour Of RC Flanged Beams Strengthened With Glass FRP", International Journal of Scientific Research in Science and Technology (IJSRST), Online ISSN : 2395-602X, Print ISSN : 2395-6011, Volume 6 Issue 2, pp. 361-368, MarchApril 2019. Available at doi :

https://doi.org/10.32628/IJSRST196260

Journal URL : http://ijsrst.com/IJSRST196260

\section{Cite this article as :}

